\title{
FUENTES NORMATIVAS PARA EL TRATAMIENTO DE LA RESPONSABILIDAD DEL PORTEADOR EN EL TRANSPORTE AÉREO. EL CONTENIDO DE LAS REMISIONES DEL CÓDIGO AERONÁUTICO AL DERECHO COMÚN Y A LOS USOS, COSTUMBRES Y PRINCIPIOS GENERALES DEL DERECHO
}

Regulatory Sources for the Treatment of Carrier's Liability in Air Transport the Content of the References in the Aeronautic Code to the Common Law and to the Uses, Customs and General Principles of Law

\author{
Claudia MejíAs Alonzo* \\ Pontificia Universidad Católica de Valparaíso \\ ANGELA TOSO MILOS** \\ Pontificia Universidad Católica de Valparaíso
}

\section{RESUMEN}

Este artículo tiene por objeto precisar el alcance del artículo 60 del Código Aeronáutico, en el ámbito de la responsabilidad del porteador en el contrato de transporte aéreo. Su aplicación suscita una serie de cuestionamientos generados a partir de las diversas fuentes a las que dicha disposición nos remite. Pretendemos contribuir a determinar su real sentido, propiciando la seguridad del tráfico jurídico aeronáutico.

\section{PALABRAS CLAVE}

Transporte aéreo, sistema de fuentes, código aeronáutico

\section{ABSTRACT}

The purpose of this paper is to specify the scope of article 6 of the Aeronautic Code, within the field of responsibility of the carrier in the contract of air transport. Its application raises a number of questions from the various sources to which it refers. We intend to contribute to determine its real meaning, favoring the certainty of the legal aeronautical traffic.

\section{KEYWORDS}

Air Transport, System of Sources, Aeronautic Code

\section{Introducción}

Cuando el legislador decimonónico elaboró el Código de Comercio, jamás imaginó la aparición del transporte aéreo y menos la importancia que este alcanzaría en el tráfico mercantil nacional e internacional, durante los siglos siguientes ${ }^{1}$. Es por esto que nuestra codificación

\footnotetext{
* Doctora en Derecho, Pontificia Universidad Católica de Valparaíso. Profesora de derecho civil, Pontificia Universidad Católica de Valparaíso, Valparaíso, Chile. Correo electrónico: claudia.mejias@pucv.cl.

** Doctora en Derecho, Universidad de Salamanca, España. Profesora de derecho comercial, Pontificia Universidad Católica de Valparaíso, Valparaíso, Chile. Correo electrónico: angela.toso@pucv.cl.

${ }^{1}$ De hecho, en 1867 - cuando entró en vigor dicho cuerpo legal- aún no se realizaba el primer vuelo en avión, el cual tuvo lugar en 1903. Transcurrido más de un siglo desde este acontecimiento, durante 2019, han salido y llegado a Chile cerca de 8.500 .000 pasajeros y se han transportado casi 274.000 .000 de kilogramos de carga, desde y hacia nuestro país. Información disponible en: https://bit.ly/3ugKaDe [visitado el 22 de octubre de 2019].
} 
comercial contempla únicamente la regulación del contrato de transporte terrestre y marítimo, en sus libros II y III, respectivamente?

La necesidad de regular el contrato de transporte aéreo en Chile surgió a partir del año 1929, cuando se crearon las Líneas Aéreas Nacionales ${ }^{3}$. Actualmente, este contrato se encuentra regulado en el Código Aeronáutico, particularmente, en sus artículos 126 y siguientes, que forman parte del Capítulo V, ubicado en el Título VIII. Precisamente, el artículo 126 del Código Aeronáutico define el contrato de transporte aéreo como "...aquel en virtud del cual una persona, denominada transportador, se obliga, por cierto precio, a conducir de un lugar a otro, por vía aérea, pasajeros o cosas ajenas y a entregar éstas a quienes vayan consignadas". A continuación, en su Capítulo I, Título IX se formula un régimen de responsabilidad para el porteador aéreo, el cual tiene un carácter predominantemente objetivo ${ }^{4}$.

Precisar la normativa que resulta aplicable a este contrato es fundamental para garantizar la seguridad del tráfico jurídico aéreo. Al respecto, debemos tener presente el artículo 6o del Código Aeronáutico, que dispone: "[E]n lo no previsto en este código ni en los convenios o tratados internacionales aprobados por Chile, se aplicarán las normas del derecho común chileno, los usos y costumbres de la actividad aeronáutica y los principios generales de derecho".

El objetivo de este trabajo es determinar la real extensión de la remisión normativa que efectúa el referido artículo 60, tratándose del contrato de transporte aéreo, de mercancías y personas, específicamente, en lo referido al régimen de responsabilidad aplicable al porteador. En este ámbito, se pretende desentrañar su sentido y alcance, con relación al orden de prelación de fuentes que plantea esta disposición, en la aplicación del Código Aeronáutico y de los convenios o tratados internacionales aprobados por Chile, así como respecto al reenvío que efectúa el artículo al derecho común chileno; a los usos y costumbres de la actividad aeronáutica; $y$, a los principios generales de derecho. Cuestión que cobra especial interés para la resolución de todos aquellos problemas que no estén expresamente reglados o que solo lo estén en uno de estos cuerpos normativos, así por ejemplo, los supuestos de cancelación del vuelo o denegación de embarque solo están reglados en el Código Aeronáutico y no en la normativa internacional; la entrega de mercancías o carga a un destinatario equivocado, no está expresamente prevista.

El Código Aeronáutico coexiste con aquellos tratados internacionales actualmente en vigor en materia de transporte aéreo. Es el caso del Convenio de Montreal, vigente en Chile desde el año 2009, que pretendió sustituir al denominado Sistema de Varsovia ${ }^{5}$. En razón de las

\footnotetext{
${ }^{2}$ El transporte terrestre es aquel que se ejecuta por tierra, lagos, canales o ríos navegables. Se rige por las normas especiales del Título V, Libro II del Código de Comercio (artículos 166 y siguientes). El contrato de transporte tiene una naturaleza eminentemente civil. En el ámbito terrestre, dicho negocio jurídico es calificado como mercantil para el transportista cuando este se encuentra organizado como una empresa (artículo 3 № 6 del Código de Comercio). Tal como apunta JEQUIER (2013), p. 137, lo mercantil en este caso no es el transporte propiamente tal sino la actividad organizada y profesional que lo actúa y permite. Por su parte, el transporte marítimo, se regula en el Título V, Libro III del Código de Comercio (artículos 974 y siguientes). Este contrato se considera comercial atendiendo al medio en el cual se ejecuta (artículo 3 № 15 del Código de Comercio). Así, "el mar mercantiliza los actos". SANDOVAL (2015), p. 112.

${ }^{3}$ Dos años más tarde, este negocio jurídico fue reglamentado a través del Decreto con Fuerza de Ley № 221, de 1931, sobre navegación aérea y, posteriormente, por medio del Decreto Ley № 2.564, de 1979. Información disponible en: https://bit.ly/3fgtNSX [visitado el 22 de octubre de 2019].

${ }^{4}$ La intención del legislador de establecer un sistema de responsabilidad objetiva se expresa en la historia de la Ley 18.916. Así, por regla general, el Código Aeronáutico prescinde de la culpa del porteador para configurar su responsabilidad, estableciendo co mo contrapartida límites cuantitativos respecto de la indemnización que puede obtener el afectado. Sin embargo, el artículo 172 de este cuerpo legal, en su inciso primero, dispone que: "[E]n todo caso el afectado por el daño podrá demandar una indemnización superior a los límites señalados en el código, si probare dolo o culpa del transportador, del explotador o de sus dependientes, cuando éstos actuaren durante el ejercicio de sus funciones". Según SANDOVAL (2014), p. 189, el Código Aeronáutico consagraría dos sistemas de responsabilidad. Uno de carácter objetivo, con indemnización limitada, y otro de responsabilidad subjetiva, sin límite de indemnización. Por su parte, BARROILHET y DÍAZ (2002), p. 434, sostienen que la introducción de elementos subjetivos para excluir el derecho a limitar la responsabilidad no importa una alteración de la naturaleza jurídica del régimen de responsabilidad objetiva.

${ }^{5}$ La denominación "Sistema de Varsovia", acogida en nuestro país, entre otros, por PRADO (2005), p. 7, obedece a las diversas modificaciones que ha experimentado el Convenio de Varsovia. Este fue publicado en el Diario Oficial con fecha 13.8.1979, y modificado por el Protocolo de la Haya, de 1955; por el Protocolo de Guatemala, de 1971, que nunca entró en vigor; y, por cua tro protocolos aprobados en Montreal el año 1975. Es por ello que suele denominarse Sistema de Varsovia. Chile ratificó el Protocolo de la Haya, publicado en el Diario Oficial con fecha 31.5.1979, y tres de los cuatro protocolos de Montreal. Los dos primeros fueron
} 
diversas controversias que se han generado, resulta relevante delimitar su real ámbito de aplicación. Por lo anterior, este será el primer cuestionamiento que resolveremos en este trabajo.

Luego nos centraremos en la remisión que se efectúa al derecho común, a fin de precisar si su contenido se limita al Código Civil. En la consecución de este objetivo, y para determinar la normativa aplicable a la responsabilidad del transportador aéreo en Chile, especial consideración tendremos de los fines de lucro del servicio de transporte aéreo, entendido como "...toda actividad destinada a trasladar, en aeronaves, a pasajeros o cosas de un lugar a otro" 6 . Se justifica esta conexión a partir de la consagración del carácter mercantil del contrato de transporte aéreo, para los transportadores que prestan el servicio de trasladar personas o mercancías por aire, con fines de lucro, como ocurre con las líneas aéreas en nuestro país.

Adicionalmente, exploraremos la posible incorporación, en la remisión al derecho común que realiza el artículo 60 del Código Aeronáutico, de la normativa prevista en la Ley 19.496 sobre protección de los derechos de los consumidores, bajo el entendido que estamos en presencia de una actividad comercial para el transportista? ${ }^{7}$.

Finalmente, precisaremos el real alcance del llamado que efectúa la disposición en estudio, a los usos y costumbres de la actividad aeronáutica y, los principios generales del Derecho. Esto resulta relevante para apreciar normativamente todas las fuentes de las que pueden emanar las obligaciones que asumirá el transportador aéreo, lo que incidirá, a su vez, en su posible responsabilidad.

Para efectuar el análisis propuesto, se emplearán los métodos exegético y dogmático. Así, se propone contribuir a la determinación del sentido del artículo 6으 del Código Aeronáutico, sobre la base del tenor de la norma positiva y de los aportes que la doctrina ha formulado en esta materia. Especial atención dedicaremos al examen de las sentencias que dan cuenta de las diversas problemáticas que se presentan, así como de la falta de uniformidad de los pronunciamientos de nuestros tribunales al respecto.

\section{Aplicación del código aeronáutico y de los tratados internacionales en el marco de la responsabilidad contractual del porteador}

El artículo 60 del Código Aeronáutico, ya transcrito, establece primeramente como derecho aplicable, conjuntamente con este Código, a los "tratados internacionales aprobados por Chile". De esta forma, en materia de responsabilidad del porteador deberá aplicarse, en primer lugar, lo dispuesto en el Capítulo I, Título IX del Código Aeronáutico (artículos 142 y siguientes) y lo señalado en el Capítulo III del Convenio de Montreal (artículos 17 y siguientes).

El Convenio de Montreal pretende sustituir al antiguo Sistema de Varsovia. Sin embargo, esta sustitución ha operado de forma paulatina, ya que este último aplica a aquellos contratos de transporte celebrados antes del año 2009. Por otra parte, dicha sustitución no se producirá totalmente sino hasta que ratifiquen el Convenio de Montreal la totalidad de los Estados que tengan ratificada alguna o algunas de las versiones del Convenio de Varsovia ${ }^{8}$.

Uno de los aspectos fundamentales del particular régimen de responsabilidad del transportador aéreo, presente tanto en el Código Aeronáutico como en los instrumentos

publicados en el Diario Oficial, con fecha 9.12.1997 y, el cuarto, el día 16.1.2009. Por su parte, el Convenio de Montreal fue aprobado el año 1999 y adoptado en Chile diez años después, de modo que fue publicado en el Diario Oficial con fecha 16.1.2009. En cuanto a la intención que se manifiesta en este último tratado internacional en el sentido de que pueda sustituir al Sistema de Varsovia, véase el artículo 55 del Convenio de Montreal.

${ }^{6}$ Artículo 95 del Código Aeronáutico.

${ }^{7}$ Ello en virtud de lo dispuesto en el artículo 2 a) de la Ley 19.496. Luego, habrá que considerar lo indicado en el artículo 2 bis del mismo cuerpo legal.

${ }^{8}$ Por lo tanto, en la práctica, no es posible hacer prevalecer siempre el Convenio de Montreal en un transporte aéreo internacional, entre un Estado firmante de Varsovia y otro de Montreal, ya que los tribunales del primero estarán obligados a aplicar las normas del Convenio de Varsovia. Respecto de eventuales soluciones para aquellos casos en que los Estados hayan ratificado protocolos diversos en el contexto del Sistema de Varsovia, véase PRADO (2005), p. 47. Desde luego que, tal como apuntan RUEDA (2012), p. 8 y ARAGONE (2008), p. 43, esta circunstancia afecta la ansiada uniformidad del derecho mercantil internacional. 
internacionales indicados, dice relación con la formulación de límites o sumas máximas por las cuales dicho transportador debe indemnizar al cargador, consignatario o pasajero, en su caso ${ }^{9}$. Al respecto, se ha señalado que, desde el punto de vista económico, el transporte aéreo tiene un elevado costo frente a los demás (terrestre y marítimo) ${ }^{10}$. En este contexto, el establecimiento de estos límites se ha considerado como un incentivo para el desarrollo de este tipo de transporte y suele concebirse como una forma de compensar los efectos derivados de la objetivación de la responsabilidad o de la responsabilidad sin culpa que se formula para el transportador en este ámbito ${ }^{11}$. Por otra parte, la limitación de responsabilidad permitiría a los expedidores, destinatarios y pasajeros evitar procesos largos, costosos y de resultado incierto, para resarcirse de los perjuicios frente al transportador aéreo. En consecuencia, esta limitación pretende evitar o paliar lo que de aleatorio tiene la avaluación judicial de los perjuicios, al tiempo que buscaría mantener bajo control los valores de las primas que los transportadores deben enterar, para verse a cubierto frente a los riesgos que afrontan, en términos que, si no existieran dichos límites, las empresas trasladarían estos costos a los usuarios ${ }^{12}$.

El Código Aeronáutico y los instrumentos internacionales aplicables al contrato de transporte aéreo establecen límites diversos a la responsabilidad del transportador ${ }^{13}$. Otra notable diferencia, que es posible apreciar al momento de perseguir la responsabilidad del porteador aéreo, se refiere a los plazos de prescripción de las acciones que pueden intentarse en su contra. Así, mientras en los artículos 29 del Sistema de Varsovia y 35 del Convenio de Montreal se indica que este plazo es de dos años, el artículo 175 del Código Aeronáutico señala que dicho periodo es de un año.

Teniendo en cuenta las diferencias que ostentan estos instrumentos con relación al régimen de responsabilidad del transportador aéreo ${ }^{14}$, resulta fundamental tener claridad acerca del orden de prelación en la aplicación del Código Aeronáutico y de los tratados internacionales existentes en esta materia. En este contexto, resulta necesario dilucidar, previamente, si realmente se presenta una antinomia o colisión normativa.

Para dar una adecuada respuesta debe ser precisado el ámbito de aplicación de estos cuerpos normativos $^{15}$. Si se examina lo señalado en los convenios internacionales mencionados,

\footnotetext{
9 PRADO (2005), pp. 41 y ss.

${ }^{10}$ PETIT (2007), p. 1. Por ello, según indica la misma autora, la competitividad del transporte aéreo no parece radicar en el precio, sino en la celeridad.

${ }^{11}$ Así, se ha sostenido que, si el quantum de la indemnización que este debe asumir no estuviere limitado, para la empresa aeronáutica no sería rentable, de modo que es preferible que el usuario tenga la posibilidad de obtener un resarcimiento limitado, a que acceda a una indemnización sin límites que no pueda ser pagada por un transportador insolvente VIDELA (1976), p. 373 y FOX (2011), p. 30.

12 TOMASELLO (1994), pp. 68-69 y HANANÍAS (2003), p. 375.

${ }^{13}$ De este modo, tratándose de la responsabilidad del porteador por la pérdida o avería de la mercancía, tanto el sistema de Varsovia vigente en Chile, ajustado por los protocolos de Montreal, como el Convenio de Montreal, establecen un límite a dicha responsabilidad: 17 Derechos Especiales de Giro por kilogramo de peso bruto de la carga perdida o averiada (artículo 22 Sistema de Varsovia y Convenio de Montreal). Por su parte, el Código Aeronáutico formula, en este ámbito, un límite que asciende a 1 Unidad de Fomento por kilogramo de peso bruto de la carga siniestrada (artículo 149 Código Aeronáutico). En el caso del transporte aéreo de pasajeros, el Sistema de Varsovia establece que la responsabilidad del porteador se limita a 16.600 Derechos Especiales de Giro por pasajero (artículo 22.1.). Respecto del equipaje, al igual como ocurre en el caso del transporte de mercancías, el límite es de 17 Derechos Especiales de Giro por kilogramo [artículo 22.2.a)]. Por su parte, el Convenio de Montreal establece que, en caso de muerte o lesiones de los pasajeros, si el daño no excede los 100.000 Derechos Especiales de Giro, el porteador no podrá excluir ni limitar su responsabilidad. Si el daño excede dicha cantidad, el transportista no será responsable si prueba que este "...no se debió a la negligencia o a otra acción u omisión indebida del transportista o sus dependientes o agentes; o b) el daño se debió únicamente a la negligencia o a otra acción u omisión indebida de un tercero" (artículo 21.1 y 21.2.). Por último, en el transporte de equipajes la responsabilidad del transportista en caso de destrucción, pérdida, avería o retraso se limita a 1.000 Derechos Especiales de Giro por pasajero (artículo 22.1.). Por su parte, el Código Aeronáutico (artículo 144), tratándose del transporte de pasajeros, en caso de muerte o lesiones, limita la indemnización a una suma que no puede exceder a las 4000 U.F. por cada pasajero. En caso de retardo en la ejecución del transporte, se limita a 250 UF por cada uno de los pasajeros.

${ }^{14}$ Así se reconoce en la sentencia de la Corte de Apelaciones de Santiago, Rol № 5238-2005, de 8 de octubre de 2008: “1o. (...) tanto el Código Aeronáutico, en sus artículos 142 y siguientes, como el Convenio para la Unificación de Ciertas Reglas Relativas al Transporte Aéreo Internacional, en sus artículos 17 y siguientes, contienen reglas que regulan la responsabilidad en el transporte aéreo. Ambos cuerpos legales, en lo fundamental (...) contienen normas similares, pero se aprecian, sin embargo, algunas diferencias...".

${ }^{15}$ Tal como indica ORELLANA (2000), p. 816, este principio se recoge en el aforismo "lo especial se aplica con preferencia a lo general" y responde, según GUZMÁN (1989), pp. XXXVI-XXXVII a la noción lógica-técnica de la primacía de la especie sobre el género.
} 
estos aplican a todo transporte aéreo internacional de personas, equipaje o carga, a cambio de una remuneración. A estos efectos, se entiende por transporte aéreo internacional

[...]todo transporte en que, conforme a lo estipulado por las partes, el punto de partida y el punto de destino, haya o no interrupción en el transporte o transbordo, están situados, bien en el territorio de dos Estados Partes, bien en el territorio de un solo Estado Parte si se ha previsto una escala en el territorio de cualquier otro Estado, aunque éste no sea un Estado parte. El transporte entre dos puntos dentro del territorio de un solo Estado Parte, sin una escala convenida en el territorio de otro Estado, no se considerará transporte internacional para los fines del presente Convenio ${ }^{16}$.

Acotado en estos tratados su ámbito de aplicación, no existe realmente una colisión normativa. De este modo, el Código Aeronáutico ha de ser aplicado al transporte aéreo nacional, mientras que los instrumentos internacionales indicados, se deben aplicar al contrato de transporte aéreo internacional ${ }^{17}$.

Pese a ello, no han sido pocos los casos en que las líneas aéreas, al ser demandadas para obtener la indemnización de aquellos perjuicios derivados del incumplimiento de un contrato de transporte aéreo internacional, celebrado antes del año 2009, han sustentado la aplicación del Código Aeronáutico en materia de prescripción. Muchas veces, estas pretensiones han sido acogidas en primera instancia. Sin embargo, las Cortes de Apelaciones y la Corte Suprema, han reiterado, en numerosas oportunidades, la aplicación del Sistema de Varsovia ${ }^{18}$. Al respecto, la Corte Suprema ha señalado que:

[T]ERCERO: (...) para rechazar la aplicación de la Convención de Varsovia, los jueces del grado señalaron que teniendo en consideración que el Código Aeronáutico fue aprobado por Ley $\mathrm{N}^{\circ}$ 18.916, publicada en el Diario Oficial el 8 de febrero de 1990, y que el Convenio de Varsovia fue aprobado el 12 de octubre de 1929 y publicado en el Diario Oficial el 13 de agosto de 1979, esto es, casi 11 años antes que el mencionado Código, «se atendrá sobre el tema sublite a las prescripciones de este último», entendiendo que sólo en caso de ausencia de norma, debería remitirse al Convenio Internacional de Varsovia. (...) CUARTO: (...) es posible colegir que el Código Aeronáutico sólo recibe aplicación cuando nos encontramos en presencia de un transporte nacional de mercaderías, es decir, cuando éste se efectúa exclusivamente dentro de los límites territoriales en que Chile ejerce soberanía...19.

A la luz de la ubicación que ostenta el Código Aeronáutico y los tratados internacionales en nuestro ordenamiento jurídico, la jurisprudencia nacional ha determinado, acertadamente, que el primero no deroga el segundo. Luego, el artículo 60 del Código Aeronáutico debe interpretarse en el sentido que dicho cuerpo legal resulta aplicable a la responsabilidad en que pueda incurrir el porteador aéreo en el transporte nacional y los tratados vigentes en esta

\footnotetext{
${ }^{16}$ Artículo 1.2. del Convenio de Montreal. En un sentido muy similar, véase el artículo 1.2. del Convenio de Varsovia. Esta definición de transporte aéreo internacional es prácticamente idéntica a aquella que se recoge en el artículo 97 del Código Aeronáutico.

${ }^{17}$ Este argumento se recoge en Corte Suprema, Rol № 3286-2009, de 23 de marzo de 2011, en los siguientes términos: "[P]or otra parte el tenor del citado artículo 10 del Código Aeronáutico resulta plenamente coherente con el contenido de las actas en que se manifiesta la historia fidedigna de la ley, de las que se desprende como principal motivo que determinó la dictación del aludido cuerpo legal, el reafirmar la soberanía plena y exclusiva de Chile sobre el espacio aéreo nacional...". En este mismo sentido, y a propósito del transporte aéreo de pasajeros, véase Corte Suprema, Rol № 562-2009, de 15 de septiembre de 2010 y Corte de Apelaciones de Valparaíso, Rol № 188-2012, de 19 de junio de 2012. Por lo anterior llama la atención advertir en demandas la invocación de la aplicación de los Convenios de Varsovia o Montreal fundado en una especial supremacía constitucional de los mismos, con relación al Código Aeronáutico, entre otros véase Corte Suprema, Rol № 200-2010, de 11 de agosto de 2011.

${ }^{18}$ Al respecto, véanse Corte Suprema, Rol № 1501-2008, de 26 de agosto de 2009; Corte Suprema, Rol № 3069-2008, de 13 de enero de 2010; Corte de Apelaciones de Santiago, Rol № 793-2009, de 6 de noviembre de 2009; Corte de Apelaciones de Santiago, Rol № 9179-2003, de 4 de agosto de 2006; Corte Suprema, Rol № 4394-2005, de 3 de julio de 2007; Corte Suprema, Rol № 3286-2009, de 23 de marzo de 2011.

${ }^{19}$ Corte Suprema, Rol № 3069-2008, de 13 de enero de 2010. En esta misma línea, en Corte de Apelaciones de Santiago, Rol № 9179-2003, de 4 de agosto de 2006, se indica: “3. Que respecto de la legislación aplicable (...) esta Corte comparte el criterio de la sentencia en alzada, en cuanto considera que resulta aplicable la Convención de Varsovia La Haya, toda vez que se trata de un transporte aéreo de carácter internacional (...) debiendo desestimarse la alegación de la parte demandante en el sentido de que este Convenio ha sido derogado por el Código Aeronáutico, por el hecho de haber sido dictado con posterioridad. Ambos cuerpos legales se encuentran vigentes; ocurre, simplemente, que sus campos de aplicación son distintos...".
} 
materia, en el transporte internacional. Esta distinción resulta fundamental cuando se trata de determinar el plazo de prescripción de las acciones orientadas a perseguir la responsabilidad del porteador, debido al dinamismo propio del transporte, que aconseja que las reclamaciones que surjan respecto de la ejecución del contrato sean zanjadas cuanto antes ${ }^{20}$. En este contexto, es necesario proporcionar el mayor grado de seguridad jurídica posible a todos los involucrados.

Nuestros tribunales superiores también han sustentado la aplicación del Sistema de Varsovia por sobre el Código Aeronáutico, en relación con los límites de responsabilidad del transportador en los contratos de transporte aéreo internacional de mercaderías, que son más bajos que aquellos contemplados a nivel interno. En primera y segunda instancia se ha fallado de conformidad al Código Aeronáutico, en circunstancias que se trataba del incumplimiento de un contrato de transporte aéreo internacional. La Corte Suprema reitera que "...el Código Aeronáutico sólo recibe aplicación cuando nos encontramos en presencia de un transporte aéreo nacional de mercaderías, es decir, cuando éste se efectúa exclusivamente dentro de los límites territoriales en que Chile ejerce soberanía" ${ }^{21}$.

A través de esta jurisprudencia se ha evitado que, en la búsqueda de compensaciones dinerarias mayores para un interés concreto, se pierda el verdadero sentido de lo que es preceptivo, como el compromiso internacional que es un tratado ${ }^{22}$. De forma tal que, para dejar de aplicar debidamente un tratado internacional corresponde que previamente sea denunciado conforme a las normas que regulan esta materia. Si un Estado de forma unilateral establece la derogación de un tratado a través de su legislación interna, puede incurrir en responsabilidad internacional ${ }^{23}$. Aclaración que cobra especial interés porque, como veremos, en más de una ocasión se han resuelto cuestiones aplicando otra normativa interna, prescindiendo de estos cuerpos normativos.

\section{Sentido y alcance de la expresión derecho común contenida en el artículo 6 del código aeronáutico en materia de responsabilidad del porteador aéreo}

El artículo 60 del Código Aeronáutico, menciona como fuente subsidiaria, las normas de derecho común chileno junto con otras fuentes (usos, costumbres de la actividad aeronáutica y principios generales del derecho). No obstante aparecer, en principio, en un mismo orden de prelación normativa, entendemos por aplicación de las reglas presentes en el sistema de fuentes que deben primar y tener, por ende, una aplicación preferente las fuentes formales que son calificadas de principales ${ }^{24}$.

A continuación, pretendemos perfilar el contenido de la noción de derecho común.

\section{El Código Civil como 'derecho común'}

De acuerdo con lo señalado en la disposición objeto del presente análisis, tratándose de la responsabilidad contractual del porteador aéreo, el derecho común debiera recibir aplicación en todo lo no previsto en el Título VIII del Código Aeronáutico, particularmente, en los artículos 126 y siguientes y en el Título IX del mismo cuerpo legal (artículos 142 y siguientes) o de los tratados internacionales, dependiendo del caso. En este contexto, cabe preguntarse acerca del contenido de esta noción.

Se trata de un término que si bien es reconocido en nuestro ordenamiento jurídico carece de un contenido legalmente definido. Sin embargo, aquello que se identifica como derecho común se le reconoce una función supletoria en el sistema de fuentes, a partir de su carácter

\footnotetext{
20 GARCÍA (2013), p. 426.

${ }^{21}$ Corte Suprema, Rol № 200-2010, de 11 de agosto de 2011. En la misma dirección, Corte Suprema, Rol № 6237-2009, de 20 de abril de 2011; Corte Suprema, Rol № 3890-2009, de 6 de abril de 2011; y, Corte Suprema, Rol № 5300-2006, de 24 de abril de 2008. ${ }^{22}$ CORBRÁN (2010), p. 5.

${ }^{23}$ Corte Suprema, Rol № 4394-2005, de 3 de julio de 2007 y Rol № 5300-2006, de 24 de abril de 2008.

${ }^{24}$ SQUELLA (2011), p. 300.
} 
general, ya sea para colmar un vacío o laguna legal, ya sea para dotar de contenido a conceptos, categorías e instituciones que se recogen en otras leyes ${ }^{25}$. Como es sabido, la primera identificación que la doctrina nacional hace de esta expresión es con el texto del Código Civil. Esto se justifica por razones históricas y encuentra su fundamento normativo en el artículo 4응 de dicho cuerpo legal ${ }^{26}$. Este sentido de la expresión derecho común, ha sido reconocido por la jurisprudencia nacional en este ámbito de la responsabilidad. Así, numerosas sentencias de nuestros tribunales invocan diversos artículos del Código Civil, particularmente aquellos que establecen conceptos o premisas de general aplicación en materia contractual, como es el caso de la fuerza obligatoria de los contratos (artículo 1545 CC); el principio de buena fe (artículo 1546 CC); la culpa (artículos 44, 1547 CC); o, la carga probatoria (artículo 1698)27. Esta aplicación supletoria del Código Civil puede explicarse, en lo sustancial, porque el de transporte es, esencialmente, un contrato civil, de modo que se reconoce una raíz común a partir de la cual se ha construido la regulación de este negocio jurídico en el Código Aeronáutico, quedando ligada a la misma por la denominación de sus institutos centrales $y$, fundamentalmente, por sus principios $^{28}$. Desde esta perspectiva, el Código Civil se comporta como una legislación general y supletoria ${ }^{29}$.

Sin embargo, esta visión tradicional del derecho común se ha visto desbordada en razón de la aplicación supletoria, por parte de nuestros tribunales, de otros cuerpos legales distintos al Código Civil, en ausencia de disposiciones específicas contenidas en el Código Aeronáutico que puedan contribuir a la determinación de la responsabilidad del transportador aéreo. Este escenario - que no es infrecuente en nuestro ordenamiento jurídico- conlleva a que el derecho común, a partir de la función que le es reconocida en el sistema de fuentes, puede estar contenido tanto en legislación general como especial ${ }^{30}$.

\section{La inclusión del Código de Comercio en la noción de 'derecho común'}

El Derecho Comercial es un derecho especial y, en tal calidad, recibe aplicación únicamente en aquellos casos que la ley lo señala ${ }^{31}$. En Chile, tradicionalmente, la mercantilidad de un acto o contrato ha emanado del artículo 3 o del Código de Comercio, al cual se le atribuye, por la doctrina mayoritaria, un carácter eminentemente taxativo ${ }^{32}$. Sin embargo, dicha norma ha sido largamente superada por las necesidades del tráfico y por la evolución del propio derecho comercial, en términos tales que actualmente es posible reconocer diversas disposiciones que consagran la mercantilidad extramuros del artículo 3 o del Código de Comercio, especialmente, en materia de organización jurídica de la empresa ${ }^{33}$.

En este marco encontramos lo dispuesto en el artículo 95 del Código Aeronáutico, que reconoce la existencia de la aeronáutica comercial, definiéndola como aquella "...que tiene por objeto prestar servicios de transporte aéreo y de trabajos aéreos, con fines de lucro". A

\footnotetext{
${ }^{25}$ MEJÍAS (2018), pp. 623-627.

${ }^{26}$ MEJÍAS (2018), p. 627. CORRAL (2018), pp. 24-26, confiere al derecho civil el carácter de derecho común no solo tratándose del derecho privado sino también respecto de aquellas ramas que pertenecen al derecho público. Con una opinión diferente, cuestionado su carácter de derecho común, en relación con el derecho administrativo y, en general, respecto de las demás leyes VERGARA (2010), pp. 29-43, 53-82.

27 Solo por indicar algunas: Corte de Apelaciones de Santiago, Rol № 9179-2003, de 4 de agosto de 2006; Corte de Apelaciones de Valparaíso, Rol № 889-2008, de 3 de octubre 2008; Corte de Apelaciones de Santiago, Rol № 1896-2008, de 10 de noviembre de 2009; Corte Suprema, Rol № 447-2010, de 22 de julio de 2010; Corte Suprema, Rol № 8153-2008, de 10 de mayo de 2010 ; Corte de Apelaciones de Santiago, Rol № 177-2010, de 10 de diciembre de 2010; Corte de Apelaciones de Santiago, Rol № 3706-2014, de 27 de junio de 2014; Corte Suprema, Rol № 16882-2013, de 28 de octubre de 2014; Corte de Apelaciones de Santiago, Rol № 13882005, 4 de noviembre de 2008; y, Corte de Apelaciones de Punta Arenas, Rol № 9-2019, de 21 de agosto de 2019.

${ }^{28}$ Ello sobre la base de lo señalado en ORELLANA (2000), p. 816. Con una opinión diferente VERGARA (2014), pp. 958, 975 y ss., sostiene que cada vez que estamos en presencia de un microsistema, identificado a partir de un núcleo dogmático, este tiene reglas y principios especiales.

${ }^{29}$ MEJÍAS (2018), p.622.

${ }^{30}$ Al respecto, véase MEJÍAS (2018), pp. 623-625.

${ }^{31}$ SANDOVAL (2015), p. 64 y PUGA (2005), p. 23.

32 Véanse, por todos, SANDOVAL (2015), p. 116 y PUGA (2005), p. 155.

${ }^{33}$ Como puede evidenciarse en los artículos 1 de la Ley 18.046, de 1981; 425 №2 del C. Com.; y 2 de la Ley 19.857 , de 2003.
} 
continuación, indica que el "[S]ervicio de transporte aéreo es toda actividad destinada a trasladar, en aeronaves, a pasajeros o cosas de un lugar a otro". En consecuencia, si bien el transporte es un contrato que reviste una naturaleza esencialmente civil, cuando este es celebrado por quienes prestan servicios de transporte aéreo, con fines de lucro, dicho negocio jurídico será considerado comercial para el porteador, ya que la mercantilidad de este giro viene determinada por lo señalado en el artículo 95 del Código Aeronáutico. De esta manera, se agrega una hipótesis más de mercantilidad situada fuera del artículo 3 o del Código de Comercio, compatible con aquella calidad que el legislador decimonónico atribuyó en su momento al contrato de transporte marítimo (artículo 3 №15 Código de Comercio) y al de transporte terrestre (artículo 3 №6 Código de Comercio), cuando este es celebrado por una empresa, en un momento en que no podía vislumbrarse la existencia del transporte aéreo ni la relevancia que este representa actualmente para el tráfico comercial. Teniendo esto en cuenta, en el marco de la determinación de la responsabilidad del porteador aéreo, nuestros tribunales han señalado que: "corresponde en primer término, la aplicación de las normas del Código de Comercio..." ${ }^{34}$, en el contexto de la remisión al derecho común que hace el artículo 6ㅇ.

Desde esta perspectiva, el Código Aeronáutico se estaría comportando como una ley mercantil especial frente al Código de Comercio, en tanto continente del derecho comercial general. Tratándose de la responsabilidad del transportador aéreo, nuestros tribunales han acudido supletoriamente a las normas del Código de Comercio, al momento de analizar el contenido de la carta de porte aéreo o air waybill, que es aquel documento que otorgan las partes para probar la celebración del contrato de transporte aéreo de mercancías y sus estipulaciones (artículos 137 y 139 del Código Aeronáutico). Atendidos los antecedentes de los que da cuenta la carta de porte, la información contenida en ella respecto de las mercaderías es muy importante para determinar la responsabilidad del porteador por las pérdidas o averías que aquellas puedan sufrir. Así, la Corte de Apelaciones de Valparaíso ha señalado que:

[S]éptimo: Que, de conformidad a lo prevenido en (...) el artículo 60 del Código Aeronáutico (...) el artículo 185 del Código de Comercio, libera de responsabilidad al porteador de las pérdidas o averías que sufrieren los efectos que no se han expresado en la carta de porte (....) no se señaló en documento mercantil alguno tal circunstancia, no dando cumplimiento a lo prevenido en el artículo 137 del Código Aeronáutico, en cuanto debió contener la carta de porte aéreo, entre otras menciones, la naturaleza y estado de las mercaderías... ${ }^{35}$.

La aplicación de un derecho especial, como aquel contenido en el Código de Comercio para determinar la responsabilidad del porteador aéreo, da cuenta del contenido amplio que ostenta la expresión derecho común, empleada en el artículo 6o del Código Aeronáutico. Así, esta noción no puede identificarse exclusivamente con el texto del Código Civil ni con un conjunto de normas que forman parte de una rama o área del derecho determinada ${ }^{36}$, argumento que se refuerza al constatar que, en materia de responsabilidad del transportador aéreo, nuestros tribunales también han invocado en diversas ocasiones la Ley 19.496, sobre protección de los derechos de los consumidores, como normativa supletoria, punto que será abordado a continuación.

Una cuestión relevante a dilucidar es determinar qué prevalencia existe entre el Código de Comercio y el Código Civil, ambos cuerpos normativos que al cumplir este rol supletorio quedan comprendidos en la expresión derecho común. Entendemos que, en virtud de lo dispuesto en los artículos 40 y 22 del Código Civil, así como en los artículos 2o y 96 del Código de Comercio, es este último el que tiene una aplicación prioritaria. Adicionalmente, puede tenerse en cuenta que la intención inicial del legislador fue instar a que se invocara el Código de

\footnotetext{
${ }^{34}$ Considerando 14, Primer Juzgado de Letras de San Felipe, Rol № 19.235, de 24 de enero de 2008, razonamiento que luego hace suyo Corte de Apelaciones de Valparaíso, Rol № 889-2008, de 3 de octubre de 2008 y Corte Suprema, Rol № 447-2010, de 22 de julio de 2010.

${ }^{35}$ Corte de Apelaciones de Valparaíso, Rol № 889-2008, de 3 de octubre de 2008.

${ }^{36}$ MEJÍAS (2018), p. 626.
} 
Comercio con preferencia al Código Civil, cuando existieren lagunas en el Código Aeronáutico, precisamente, porque la codificación mercantil se presenta como una ley especial frente al Código $\mathrm{Civil}^{37}$. En la misma dirección, se han pronunciado nuestros tribunales respecto del plazo de prescripción de la acción del transportista por el cobro del transporte efectuado, ocasión en que se ha discutido si resultaba aplicable el plazo de prescripción previsto en el artículo 2522 del Código Civil o el plazo que prevé el artículo 822 del Código de Comercio. La Corte Suprema ha concluido, invocando el artículo 6으, que debe considerarse, ante la ausencia de regulación en el Código Aeronáutico, la naturaleza jurídica de la relación de transporte y en concreto su mercantilidad, para dar una aplicación preferente al Código de Comercio ${ }^{38}$.

\section{Aplicación de la ley 19.496 en el marco del artículo 60 del Código Aeronáutico}

En el marco de la responsabilidad del porteador aéreo, la aplicación de la Ley 19.496 no ha estado exenta de controversias. En un principio, era frecuente que los jueces de Policía Local se declararan incompetentes para conocer aquellas diferencias suscitadas entre las partes en este ámbito. Esta postura fue sustentada invocando el artículo 6ㅇ del Código Aeronáutico y el artículo 2 bis a) de la Ley 19.496, conforme a los cuales no correspondía aplicar dicho cuerpo legal, por cuanto el Código Aeronáutico contempla normas relativas a la responsabilidad del transportador aéreo. De este modo, se señaló que estos asuntos debían ser conocidos por los juzgados civiles ${ }^{39}$. En consecuencia, en una primera etapa, la Ley 19.496 no se consideró incluida dentro de la noción de derecho común consagrada en el artículo 6 del Código Aeronáutico.

Sin embargo, la aplicación de la Ley 19.496 a las controversias surgidas a propósito del incumplimiento, por parte de las compañías aéreas, de sus obligaciones emanadas de aquellos contratos de transporte celebrados con consumidores ha sido cada vez más frecuente ${ }^{40}$. En algunas de las resoluciones judiciales pronunciadas en este sentido se ha sustentado la aplicación de la Ley 19.496. Por una parte, se invoca la responsabilidad objetiva de las agencias de viajes, ante el incumplimiento del contrato de transporte aéreo por las aerolíneas, acudiéndose al artículo 43 de la Ley ${ }^{41}$. Por otra, en lo que dice relación con el procedimiento

\footnotetext{
${ }^{37}$ De hecho, en la historia de la Ley 18.916 aparece que el proyecto del Código Aeronáutico consagraba inicialmente, de forma expresa, la aplicación prioritaria del Código de Comercio, mediante la incorporación de la siguiente disposición: "[A]rtículo 144. En lo no previsto por las normas que rigen los contratos de este título, regirán las disposiciones del Código de Comercio y del Código Civil que sean aplicables". Luego, esta norma fue sustituida por el texto actual del artículo 6o del Código Aeronáutico. La explicación que se da para ello es que "...no obstante que el Código es, en esencia, un completo conjunto sistematizado y armónico de normas (...), resulta imposible prever en él, por tratarse de una materia que constituye una rama especial del derecho, la solución de situaciones generales que normalmente regula el derecho común" (Informe Comisión Conjunta, de 6 de septiembre de 1989). De este modo, la expresión "derecho común" comprendería, en primer lugar, al Código de Comercio y luego al Código Civil. Véase BIBLIOTECA DEL CONGRESO NACIONAL (1990).

${ }^{38}$ Corte Suprema, Rol № 1876-2000, de 3 de octubre de 2001. Sentencia acordada con el voto en contra del Ministro Juica, quien argumenta que la normativa aplicable es el Código Civil, por cuanto el artículo 822 del Código de Comercio establece que: "Las acciones que procedan de las obligaciones de que trata el presente Libro y que no tengan señalado un plazo especial de prescripción, durarán cuatro años", y la obligación de pago del precio o porte en el contrato de transporte aéreo no está consagrada en el Código de Comercio, sino en el Código Aeronáutico. En este último sentido también se pronuncia DOMíNGUEZ (2014), pp. 398-399. Es una cuestión discutible, no obstante, en razón de la mercantilidad atribuible al contrato de transporte aéreo y del principio de especialidad encuentra asidero lo señalado en esta resolución por el voto de mayoría.

${ }^{39}$ Al respecto, MOMBERG (2003), p. 228, fue categórico al señalar en su momento que el Código Aeronáutico “...se encarga de regular en su integridad todo lo referente a la prestación de servicios de transporte aéreo, al contrato de transporte aéreo y a las eventuales sanciones, responsabilidades e indemnizaciones que por causa de éstos se puedan originar, de manera que no puede entenderse que existan materias no previstas por dicho Código que pudiesen dar lugar a la aplicación de la Ley № 19.496”. En este sentido véanse, por ejemplo, Corte Suprema, Rol № 1753-2008, de 6 de abril de 2009 y Corte de Apelaciones de Santiago, Rol № 101.751-2011, de 12 de abril de 2012.

${ }^{40}$ En este sentido, véanse Corte de Apelaciones de Santiago, Rol № 4205-2007, de 5 de enero de 2007; Corte de Apelaciones de Coyhaique, Rol № 11-2010, de 20 de abril de 2010; Corte de Apelaciones de Coyhaique, Rol № 22-2010, de 25 de agosto de 2010; Corte de Apelaciones de Antofagasta, Rol № 178-2016, de 14 de febrero de 2017; Corte de Apelaciones de Antofagasta, Rol № 372017, de 12 de mayo de 2017; Corte Suprema, Rol № 40.806-2017, de 5 de marzo de 2018; Corte Suprema, Rol № 2725-2018, de 7 de marzo de 2019; y, Corte de Apelaciones de Punta Arenas, Rol № 9-2019, de 21 de agosto de 2019.

${ }^{41}$ Corte de Apelaciones de Punta Arenas, Rol № 290-2007, de 23 de mayo de 2008; Corte de Apelaciones de Concepción, Rol № 331-2013, 11 de abril de 2014; Corte de Apelaciones de Santiago, Rol № 2336-2008, 6 de agosto de 2008, Corte de Apelaciones de Santiago, Rol № 5677-2008, de 26 de septiembre de 2008; Corte de Apelaciones de Valparaíso, Rol № 188-2012, de 19 de junio de 2012; y, Corte Suprema, Rol № 9816-2019, de 22 de agosto 2019.
} 
para perseguir la responsabilidad del transportador aéreo, señalando que estos asuntos, en lo sustantivo, debieran solucionarse invocando las normas del Código Aeronáutico. Lo anterior sobre la base de lo establecido en el artículo 2 bis c) de la Ley $19.496^{42}$.

Desde la perspectiva del artículo 60 del Código Aeronáutico, la aplicación de la Ley 19.496 en materia de responsabilidad contractual del porteador aéreo implica pasar a una segunda etapa, en la cual este cuerpo legal debiera considerarse incluido en la noción de derecho común. Esta inclusión procederá cuando se trate de una materia que no se encuentre prevista en el Código Aeronáutico, en virtud de lo dispuesto en el artículo 2 bis a) de la Ley 19.496, o bien, en razón de lo señalado en el artículo 2 bis b) de dicho cuerpo legal, con relación al procedimiento para hacer efectiva la responsabilidad contractual del porteador.

Un hito importante vinculado a la aplicación de la Ley 19.496 a los contratos de transporte aéreo celebrado con consumidores, viene dado por lo señalado en la Ley 20.831 , de 2015 , que modificó diversas disposiciones del Código Aeronáutico e incorporó a dicho cuerpo legal el nuevo artículo $133 \mathrm{~F}$, que indica que:

[L]as acciones individuales o colectivas destinadas a sancionar las infracciones a las normas contenidas en este Párrafo y a la obtención de las prestaciones, reparaciones e indemnizaciones que en él se establecen, se tramitarán conforme al procedimiento y ante los tribunales señalados en el Título IV de la ley № 19.496, sobre protección de los derechos de los consumidores, y para efectos de lo dispuesto en esta ley, será también competente, a elección del pasajero, el tribunal de su domicilio.

Esta modificación legislativa significa que la aplicación de la Ley 19.496, en aquellos aspectos procedimentales asociados a la responsabilidad del porteador aéreo y respecto del cumplimiento de las obligaciones señaladas en el párrafo 1, Capítulo V, Título VIII del Código Aeronáutico ${ }^{43}$, está consagrada expresamente en dicho cuerpo legal. Por lo tanto, en este específico contexto, no cabe atribuir a la Ley 19.496 el carácter de derecho común en los términos indicados en el artículo 60 del Código Aeronáutico. Esto, precisamente, porque la aplicación de la Ley 19.496 en este ámbito, procedería en razón de lo dispuesto en el artículo $133 \mathrm{~F}$ y no del artículo 6 del Código Aeronáutico, de modo que se trataría de un asunto que sí está previsto en este último cuerpo legal.

Con posterioridad a la entrada en vigor de esta norma, existe alguna resolución judicial que ha invocado la Ley 19.496 no solo con respecto a cuestiones adjetivas, sino también de fondo vinculadas a los contratos de transporte aéreo de pasajeros celebrados con consumidores y en materias no comprendidas en el artículo $133 \mathrm{~F}$, que tienen su propia regulación en el Código Aeronáutico, como es el caso de la pérdida de equipaje (artículos 134 y 148) ${ }^{44}$. Esta aplicación de la Ley 19.496 en un sentido amplio parece reforzarse por el propio Servicio Nacional del Consumidor (Sernac), a través de la Circular Interpretativa sobre las Aerolíneas y Agencias de Viaje, de marzo de 2019 ("Circular Sernac") ${ }^{45}$, en la que se señalan una serie de deberes o

\footnotetext{
${ }^{42}$ El artículo 2 bis c) de la ley 19.496 señala: “[N]o obstante lo prescrito en el artículo anterior, las normas de esta ley no serán aplicables a las actividades de (...) prestación de servicios reguladas por leyes especiales, salvo: (...) c) En lo relativo al derecho del consumidor o usuario para recurrir en forma individual, conforme al procedimiento que esta ley establece, ante el tribunal correspondiente, a fin de ser indemnizado de todo perjuicio originado en el incumplimiento de una obligación contraída por los proveedores, siempre que no existan procedimientos indemnizatorios en dichas leyes especiales". Al respecto, véase Corte de Apelaciones de Santiago, Rol № 4205-2007, de 5 de enero de 2007 y Corte de Apelaciones de Punta Arenas, Rol № 9-2019, de 21 de agosto de 2019.

${ }^{43}$ Dichas obligaciones constituyen la contrapartida de los derechos consagrados para el pasajero en dicho párrafo, que se refieren a la emisión del billete de pasaje (artículo 131); a que no se rehúse o condicione el transporte del pasajero sino en las circunstancias señaladas en la ley (artículo 132); a la adopción de una serie de medidas por parte del transportador en caso de denegación de embarque por sobreventa de pasajes, retraso o cancelación de un vuelo (artículos 133, 133 A, 133 B); a la devolución de lo pagado por el pasajero en caso de cancelación del vuelo por causas imputables al transportador (artículo 133 C); y, a la prohibición de cobrar un importe adicional al pasajero en caso que el transportador lo acomode en una clase superior por causas ajenas a su voluntad (artículo $133 \mathrm{E}$ ).

${ }^{44} \mathrm{Al}$ respecto, véase Corte de Apelaciones de Arica, Rol № 20-2016, de 7 de julio de 2016.

${ }^{45}$ Resolución exenta № 0189, de 21 de marzo de 2019. En dicha resolución el Sernac señala que: "...de acuerdo a la LPC, quienes deben asumir directamente frente a los consumidores-pasajeros la responsabilidad por los daños y perjuicios sufridos, causados
} 
principios generales del derecho del consumo que debieran aplicarse en los contratos de transporte aéreo, cuya inobservancia puede generar la responsabilidad del porteador ${ }^{46}$.

La aplicación de la Ley 19.496 a cuestiones sustantivas reguladas en el Código Aeronáutico atenta contra lo dispuesto en el artículo 60 de dicho cuerpo legal, así como contra lo señalado en el propio artículo 2 bis a) de la Ley 19.496. Sin embargo, en aquellos casos en que se invoque este último cuerpo legal para solucionar cuestiones sustantivas no contempladas en el Código Aeronáutico o adjetivas fuera del campo de aplicación del artículo $133 \mathrm{~F}$, podrá considerarse que la Ley 19.496 se está comportando como derecho común, a la luz de lo previsto en el artículo 6o del Código Aeronáutico.

Los distintos estadios en que puede encontrarse la Ley 19.496 con relación al artículo 6으 del Código Aeronáutico, no hace más que demostrar la flexibilidad que presenta la expresión derecho común contemplada en dicha norma, cuyo contenido se construye sobre la base de la dogmática jurídica y de las necesidades sociales, reflejadas en las resoluciones dictadas por nuestros tribunales. Desde esta perspectiva, la noción de derecho común consagrada en el artículo 60 del Código Aeronáutico “...permite, por su flexibilidad, proporcionar una solución adecuada al órgano encargado de las operaciones de aplicación del derecho, que se adapte a las condiciones sociales, políticas y económicas imperantes en un momento dado" ${ }^{47}$.

\section{Los usos y costumbres de la actividad aeronáutica y los principios generales del derecho}

Finalmente, el artículo 60 nos remite, como derecho supletorio, a los usos y costumbres de la actividad aeronáutica y a los principios generales del derecho. Nos interesa precisar el alcance real de esta remisión.

La noción y contenido de los principios generales del derecho han sido latamente discutidos por la doctrina ${ }^{48}$, se trate de una categoría abstracta e indeterminada que impide conferirles autonomía como fuente subsidiaria. Por esto entendemos que su reenvío resulta subsumido en la noción flexible de derecho común, a la que nos referíamos previamente. Tratándose de la responsabilidad por transporte aéreo, por sus particularidades, podremos identificar principios propios que serán extraídos de la normativa que los regula y que se encuentran estrechamente vinculados con la nueva lex mercatoria. De esta forma, creemos que no tienen realmente una aplicación autónoma sino que quedan subsumidos en las nociones referidas.

Por lo señalado, nos detendremos solo en los usos y las costumbres. Los primeros forman parte de un estado embrionario de la costumbre objetiva, que comienza

[...]con la repetición en los contratos de una estipulación determinada, hasta que la cláusula en cuestión, a fuerza de repetirse, se sobreentiende aunque deje de establecerse, para terminar siendo

\footnotetext{
producto de un incumplimiento contractual o de un actuar negligente que causa menoscabo debido a fallas o deficiencias en la calidad o seguridad del servicio de transporte aéreo, son (...) las líneas aéreas en caso de que se adquiera el ticket o pasaje aéreo directamente con ellas o a las agencias de viajes (...) En consecuencia, el consumidor-pasajero que contrata con una agencia de viajes, podrá dirigirse ante un incumplimiento en el servicio de transporte aéreo, tanto contra la agencia de viaje, como contra la aerolínea, en forma conjunta".

${ }^{46}$ En particular, esta circular se refiere al principio de irrenunciabilidad de los derechos de los consumidores; de buena fe contractual; al deber del proveedor de informar a los consumidores y a la autoridad y al principio de integración publicitaria.

47 MEJÍAS (2018), p. 638.

${ }^{48}$ Como es sabido, en doctrina se han plantado una serie de discusiones en torno a estos, que van desde su noción hasta su real contenido, que aparece vinculado a normas jurídicas y su inducción; y, número. Puede consultarse GUZMÁN (2014), pp. 69-93, en especial en relación al origen de la noción, capítulo octavo. Incluso, la doctrina hecho presente que a propósito de estos se incluyen: axiomas; máximas que los autores proponen; ideas dominantes en un sistema jurídico nacional; principios abstractos en los que se inspira una institución universal; principios que se derivan como la ratio de determinadas disposiciones vigentes en el ordenamiento jurídico; principios propios de la aplicación del derecho; y, principios superiores que informan todo el derecho. Por todos ESSER (1961), pp. 4-5. Similar TARDío (2011), pp. 9-17.
} 
al final una norma completamente objetiva que se impone a los contratantes, siempre que no exista pacto en contrario ${ }^{49}$.

En este contexto, en la noción de costumbre se reconoce un elemento subjetivo (opinio iuris) que da cuenta de la convicción del sujeto de que la conducta o práctica adoptada constituye una regla jurídica que le impone una obligación o le faculta el ejercicio de un derecho ${ }^{50}$. El artículo 6ㅇ nos remite a la aplicación de los usos y costumbres acotados a la actividad aeronáutica, por lo que cobra relevancia acudir a la nueva lex mercatoria.

Los usos y costumbres integraron la lex mercatoria ${ }^{51}$ e integran también la denominada nueva lex mercatoria ${ }^{52}$, en cualquiera de las acepciones que la doctrina ha planteado de esta. Para un sector, este concepto incluye todo tipo de prácticas, normas y usos comerciales que se desarrollan independientemente de algún sistema legal nacional, los que eventualmente pueden comprender un conjunto de normas autónomas en su existencia y en su ejecución, de los ordenamientos jurídicos de las partes contratantes, y que trasciende los ámbitos del derecho comparado. Para otros, es una categoría histórico-jurídica de usos y prácticas comerciales consuetudinarias que, mediante la aceptación coetánea de ciertas reglas de conducta por parte de los actores económicos internacionales, permiten resolver jurisdiccionalmente las controversias a través del arbitraje, además de realizar diversas transacciones comerciales ${ }^{53}$.

Como es sabido, algunos entes internacionales realizan la tarea de recopilación, fijación y creación de normas, para facilitar el comercio internacional, dando paso a una unificación no estatal, que integran la referida nueva lex mercatoria. En este contexto se insertan las entidades internacionales que colaboran en los procesos de estandarización técnica, destacando en materia de contrato de transporte aéreo de mercancías y personas, la International Air Transport Association (IATA), que elabora las llamadas Passenger and Cargo Services Conference Resolutions, que constituyen condiciones generales de los contratos de transporte aéreo de pasajeros y mercancías, adoptadas por las principales líneas aéreas alrededor del mundo ${ }^{54}$. Sus resoluciones y prácticas recomendadas para sus miembros se extienden casi a la totalidad de los aspectos del desarrollo comercial del transporte aéreo, incluyéndose medios de pago, uso de agentes de viaje, devolución del precio, contratación electrónica, catering a bordo, transporte de carga, etc. Estas condiciones generales han sido invocadas ante nuestros tribunales, en aquellos casos en que dan cuenta de reglas expresadas en los convenios de Varsovia o Montreal ${ }^{55}$ o, bien, para aludir a aquellos usos y costumbres que son recogidos en cláusulas contractuales adoptadas por las partes ${ }^{56}$.

\footnotetext{
49 SANDOVAL (2007), pp. 40-41.

50 GUZMAN (1995), pp. 623-628 y TOLEDO (1990), pp. 483-484.

51 Se trata de una noción histórica, que resolvía las cuestiones propias del comercio internacional. En la alta Edad Media, con el desarrollo de la actividad mercantil surge la necesidad de compilar los usos comerciales que regulaban la actividad, así como las decisiones o sentencias. En ese entonces, no existían estados nacionales y su aplicación se daba principalmente en ferias, lo que permitía trascender las divisiones territoriales de la época. A la ley de los comerciantes se denominó lex mercatoria, caracterizada por ser un derecho profesional, de clase y autónomo, aplicado exclusivamente a comerciantes, quienes adquirían esta calidad al pertenecer a la curia mercatorum, luego de la inscripción en el Líber. Asimismo, los tribunales especiales, conformados por los propios comerciantes, decidían las controversias que se suscitaban. Es un derecho consuetudinario, su principal fuente era la costumbre. Finalmente, se pone de relieve su carácter internacional, supranacional. Al respecto, véanse UNGUREANU (2016), pp.1112 y JUENGER y SÁNCHEZ (2000), pp. 17-18.

52 Los principios jurídicos creados y recopilados por los mercaderes durante la Edad Media fueron recogidos por el movimiento codificador y al convertirse la lex mercatoria en el derecho comercial moderno, perdió muchas de sus características. Al respecto, puede consultarse JUENGER y SÁNCHEZ (2000), pp. 17-18.

${ }^{53}$ Acerca del origen y desarrollo de la expresión, así como sus críticas por su falta de definición, ante la pluralidad de fuentes que la componen, véase LEÓN (2019), pp. 43-50.

54 LEÓN (2019), p. 113; ARROYO (2006), pp. 47-48; y, PETIT (2007). Se trata de una asociación privada, fundada por 57 compañías aéreas, en su mayoría de países de Europa y América del Norte. Esta asociación de compañías aéreas coopera en la consecución de un transporte aéreo seguro, regular y eficiente en beneficio de los pasajeros y del comercio. Actualmente, cuenta con 290 lín eas aéreas afiliadas, pertenecientes a más de 140 países del mundo, que representan alrededor del $94 \%$ del transporte aéreo internacional regular. Al respecto, véase https://bit.ly/2SkKONW [visitado el 22 de octubre de 2019].

${ }^{55}$ Corte Suprema, Rol № 200-2010, de 11 de agosto de 2011.

${ }^{56}$ Corte de Apelaciones de Santiago, Rol № 2400-2012, 21 de octubre de 2013.
} 
De esta forma, aun cuando normativamente su ámbito de aplicación podría ser más amplio, desde una perspectiva práctica, los usos y las costumbres quedan subsumidos por la aplicación de las otras fuentes del contrato de transporte aéreo, en especial, normativa expresa o cláusulas de las partes que las incorporan o nos remiten a estas a través del recurso a la lex mercatoria.

\section{Conclusiones}

1. El contrato de transporte aéreo se rige, a partir de lo dispuesto por el artículo 60 del Código Aeronáutico, primeramente por lo previsto por las partes, siempre que actúen dentro de los márgenes que el propio ordenamiento jurídico establece. En lo no previsto por estas, la primera fuente aplicable, son ciertos preceptos legales: el Código Aeronáutico y los Convenios de Montreal y Varsovia, último tratado que mantiene vigencia por razones de ultractividad de la ley.

No obstante, la errada aplicación que se ha hecho de estas fuentes, en ciertas ocasiones por nuestros tribunales, normativamente la solución a una posible controversia es clara. No existe realmente un problema de antinomia o colisión normativa, simplemente estos preceptos legales tienen un ámbito de aplicación diferenciado. El Código Aeronáutico extiende su fuerza obligatoria a controversias que se suscitan en el transporte aéreo nacional. Si el conflicto jurídico es consecuencia del transporte aéreo internacional, se aplican los convenios ya referidos.

2. En ausencia de reglamentación expresa en los cuerpos normativos indicados, el artículo 60 del Código Aeronáutico, nos remite a la aplicación del derecho común, los usos y costumbres de la actividad aeronáutica y los principios generales de derecho. A pesar de esta remisión de carácter amplio, sí es posible sostener que existe un orden de prelación de estas fuentes, sin perjuicio que su real alcance es limitado en varios casos. En este contexto, supletoriamente, el derecho común es lo primero que debe ser aplicado, ya que en la materia su contenido está conformado por fuentes formales principales.

3. Tradicionalmente, la doctrina ha identificado la noción de derecho común con un determinado cuerpo normativo, el Código Civil. Sin embargo, el reenvío no se agota en él, tal como hemos puesto de relieve, legal y doctrinalmente, esta noción es más amplia y, a partir de su función supletoria en el sistema de fuentes, comprende al Código de Comercio. El Código de Comercio, además, goza de aplicación preferente, al momento de integrar un vacío o laguna legal, fundado en el principio de especialidad - carácter mercantil del contrato de transporte aéreo- y en una interpretación armónica de los diversos cuerpos legales concernidos. Por lo anterior, si una determinada cuestión está reglada en el Código Civil y en el Código de Comercio, debe preferirse a este último cuerpo legal. En lo no previsto por el Código de Comercio, tendrá aplicación el Código Civil.

4. Integra la remisión al derecho común, por la función que se le atribuye a este, la Ley de protección de los derechos de los consumidores, en lo que dice relación con las cuestiones adjetivas, fuera del ámbito de las acciones colectivas, ya que prevalece en este último caso lo preceptuado en el artículo $133 \mathrm{~F}$ de la Ley 19.496. Con relación a los aspectos sustantivos, se ha producido una clara contravención al artículo 6이 del Código Aeronáutico, en todos aquellos casos, resueltos por nuestros tribunales, en que se ha prescindido de la aplicación de este Código, para dar paso a la aplicación preferente de la Ley 19.496, fundado en su carácter de relación de consumo. El artículo 6o permite aplicar la Ley 19.496 solo en aquellos casos en que se regule una materia que no está expresamente reglada en dicho Código.

5. Finalmente, el artículo 6o nos remite a los usos y costumbres de la actividad aeronáutica y a los principios generales del derecho. No obstante, la aparente amplitud de dicha remisión, estas fuentes quedan subsumidas en otras, ya sea el contrato adoptado por las partes, los preceptos legales nacionales o internacionales vigentes o en el contenido que puede atribuirse al derecho común. 
Aragone Coppola, Augusto (2008): “La Convención de Montreal 1999: ¿̇la nueva Convención del Varsovia?, en: CIDA-E, Revista de Centro de Investigaciones y Difusión Aeronáutico- Espacial (№ 33), pp. 39-76.

Arroyo Martínez, Ignacio (2006): Curso de Derecho Aéreo (Pamplona, Thomson Civitas).

Barroilhet AceVedo, Claudio y díaz Díaz, Alejandro (2002): Derecho del Transporte. Terrestre, Marítimo, Aéreo, Multimodal (Valparaíso, Editorial Libromar), tomo I.

Biblioteca Del Congreso Nacional (1990): "Historia de la ley 18.916". Disponible en https://bit.ly/3fGfh5R [visitado el 22 de octubre de 2019].

CORBRÁN RIZZO, ROXANA (2010): "El daño moral en el transporte aéreo frente al derecho interno y los convenios internacionales”, en: Revista Crítica de Derecho Privado (№ 7), pp. 523-545.

Corral Talciani, Hernán (2018): Curso de Derecho Civil, Parte General (Santiago, Thomson Reuters).

DOMÍNGUEZ ÁGUILA, RAMÓN (2014): La prescripción extintiva. Doctrina y jurisprudencia (Santiago de Chile, Editorial Jurídica de Chile).

ESSER, JOSEF (1961): Principio y norma en la elaboración jurisprudencial del derecho privado (Traducc. Eduardo Valentí, Barcelona, Bosch).

FOX IGUALT, CHRISTIAN (2011): Limitación de responsabilidad del armador y principio de reparación integral de los acreedores, 2a edición (Librotecnia, Santiago).

GARCía LUENGO, RAMÓN (2013): "El contrato de transporte de mercancías en régimen de conocimiento", en: Bercovitz Rodríguez-Cano, Alberto y Calzada Conde, María Ángeles (Dirs.), Contratos mercantiles, 5a edición, (Pamplona, Thomson Reuters, Aranzadi), tomo II, pp. 392467.

GuZMÁn BRITO, AlejANDRo (1989): "Sobre la historia de las nociones de derecho común y de derecho propio (prólogo), en: Bravo Lira, Bernardino, Derecho común y derecho propio en el nuevo mundo (Santiago, Editorial Jurídica de Chile), pp. XI-XXXVIII.

(1995): "El fundamento de validez de la costumbre como fuente de derecho", en: Revista Chilena de Derecho (Vol. 22, № 3), pp. 623-628.

Thomson Reuters).

(2014): El origen y la expansión de la idea de principio del derecho (Santiago,

HANANÍAS CASTILLO, RODRIGo (2003): La responsabilidad civil en el Transporte Aéreo de Mercancías, (Santiago, Editorial Jurídica La Ley).

Jequier LehuedÉ, Eduardo (2013): Curso de Derecho Comercial (Santiago, Thomson Reuters), tomo I.

JUENGER, FRIEDRICH y SÁNCHEZ, Sixto (2000): "Conflictualismo y Lex Mercatoria", en: Derecho Internacional Privado (Vol. 52, № 1), pp. 15-47.

LEÓN ROBAYO, ÉDGAR (2019): La nueva lex mercatoria en el derecho latinoamericano de contratos (Bogotá, Tirant lo Blanch-Universidad del Rosario).

Mejías Alonzo, ClAUdia (2018): "El derecho común presupuesto en el ordenamiento jurídico nacional. Una revisión de su contenido", en: Revista Chilena de Derecho (Vol. 45, № 3), pp. 621646.

Momberg URIBE, RodRIGo (2003): "Sentencia sobre la aplicación de la ley de protección de los derechos de los consumidores al contrato de transporte aéreo (Segundo Juzgado de Policía Local 
de Osorno, Corte de Apelaciones de Valdivia)", en: Revista de Derecho (Valdivia) (Vol. 15, № 2), pp. 227-230.

ORellana Retamales, LUIS (2000): "La supletoriedad de las leyes", en: Revista Chilena de Derecho (Vol. 27, № 4), pp. 807-822.

Petit LaVAlL, MARía Victoria (2007): La responsabilidad por daños en el transporte aéreo internacional de mercaderías (Granada, Comares).

Prado Donoso, Maximiliano (2005): Responsabilidad civil en el transporte aéreo. Daños a los pasajeros en el transporte internacional (Santiago, Lexis Nexis).

Puga Vial, JuAn Esteban (2005): El acto de comercio. Crítica a la teoría tradicional (Santiago, Editorial Jurídica de Chile).

Rueda VALDIVIA, RICARDo (2012): La responsabilidad del transportista aéreo (Granada, Comares).

SANDOVAL LóPEZ, RICARDo (2007): Derecho Comercial, 7ạ edición (Santiago, Editorial Jurídica de Chile), tomo I, volumen 1.

(2014): Contratos Mercantiles, 2ª edición (Santiago, Editorial Jurídica de Chile), tomo I.

(2015): Derecho Comercial (Santiago, Editorial Jurídica de Chile), tomo I.

SQUELLA NARDUCCI, AGUSTín (2011): Introducción al Derecho, 2ªedición (Santiago, Editorial Jurídica de Chile).

TARDIO, JOSÉ ANTONIO (2011): Los principios generales del derecho (Barcelona, Editorial Bosch).

TOledo TAPIA, FeRnANDo (1990): "La "opinio juris" como elemento psicológico de la costumbre", en: Revista Chilena de Derecho (Vol. 17, № 3), pp. 483-508.

TOMASELlo HART, LESLIE (1994): Estudios de Derecho Privado (Valparaíso, Edeval).

Ungureanu, CARMen (2016): "Lex Mercatoria in International Trade Contracts", en: Analele Stiintifice Ale Universitatii Alexandru Ioan Cuza Di lasi Stiinte Juridice (Vol. 62, № 5), pp. 5-28.

Vergara Blanco, Alejandro (2010): El Derecho Administrativo como Sistema Autónomo. El mito del Código Civil como "Derecho Común" (Santiago, Abeledo Perrot).

(2014): "Sistema y autonomía de las disciplinas jurídicas. Teoría y técnica de los núcleos dogmáticos”, en: Revista Chilena de Derecho (Vol. 41, № 3), pp. 957-991.

VIDELA EscaladA, Federico (1976): Derecho Aeronáutico (Buenos Aires, Víctor P. de Zavalía), tomo IV.

\section{JURISPRUDENCIA CITADA}

The Pacific Steam Navegation Company Con Greenpeace S.A. (2001): Corte Suprema 3 de octubre de 2001 (casación), en: Revista de Derecho y Jurisprudencia, Tomo 98, secc.1으, №4, pp. 197202.

KINTETSU WORLD EXPRESS USA CONTRA (2006): Corte de Apelaciones de Santiago 4 de agosto de 2006 (apelación), en: Thomson Reuters Westlaw - CL/JUR/565/2006.

APELACIÓN (2007): Corte de Apelaciones de Santiago 5 de enero de 2007 (apelación), en: CL/JUR/2414/2007.

Renta Nacional Compañía de Seguros Generales S.A. con American Airlines (2007): Corte Suprema 3 de julio de 2007 (casación), en: Vlex - 332685930. 
ROHDE AND LIESENFELD TRANSPORTES INTERNACIONALES LIMITADA CON CENTRO DE MEJORAMIENTO GENÉTICO Y REPRODUCCIÓN AVANZADA DE CAMÉLIDOS LIMITADA (2008): Primer Juzgado de Letras de San Felipe 24 de enero de 2008 (cobro de pesos), en: Thomson Reuters Westlaw - CL/JUR/5977/2008.

Renta nacional Compañía de Seguros Generales S.A. con Ceballos Pérez, Alejandro, Kintetsu WORLD EXPRESS CHILE LIMITADA (2008): Corte Suprema 24 de abril de 2008 (casación), en: Thomson Reuters Westlaw - CL/JUR/7355/2008.

Carla VÁsquez González con Skartour limitada (2008): Corte de Apelaciones de Punta Arenas 23 de mayo de 2008 (Recurso de Apelación, querella infraccional y demanda civil), Rol № 270-2007, en: https://westlawchile.cl/, Cita Online: CL/JUR/5809/2008.

José francisco Pacheco NAVARRete con TIJe Chile S.A. (2008): Corte de Apelaciones de Santiago 6 de agosto de 2008 (Recurso de Apelación, querella infraccional y demanda civil), en https://westlawchile.cl/, Cita Online: CL/JUR/3118/2008.

Patricia Araya Valenzuela; Servicio Nacional del Consumidor SERNAC con TURISMo Gente Limitada (2008): Corte de Apelaciones de Santiago 26 de septiembre de 2008 (apelación), en: Thomson Reuters Westlaw - CL/JUR/6108/2008.

ROHDE AND LIESENFELD TRANSPORTES INTERNACIONALES LIMITADA CON CENTRO DE MEJORAMIENTO GENÉTICO Y REPRODUCCIÓN AVANZADA DE CAMÉLIDOS LIMITADA (2008): Corte de Apelaciones de Valparaíso 3 de octubre de 2008 (apelación), en: Thomson Reuters Westlaw - CL/JUR/5341/2008.

Compañía de Seguros Generales Cruz del Sur S.A. con Varig S.A. (2008): Corte de Apelaciones de Santiago 8 de octubre de 2008 (apelación), en: Thomson Reuters Westlaw - CL/JUR/6116/2008.

APELACIÓN (2008): Corte de Apelaciones de Santiago 4 de noviembre de 2008 (apelación), en: Thomson Reuters Westlaw - CL/JUR/710/2008.

Mapfre Compañía de Seguros Generales Chile S.A. con World of Transport International LtDa. (2009): O.L., J.V. con Lan Airlines S.A. (2009): Corte Suprema 6 de abril de 2009 (casación), en: Vlex-55910662.

Lan Chile S.A con Aetna Chile Seguros Generales (2009): Corte Suprema 26 de agosto de 2009 (casación), en: Thomson Reuters Westlaw - CL/JUR/468/2009.

Mapfre Compañía de Seguros Generales Chile S.A. con World of Transport International LtDa. (2009): Corte de Apelaciones de Santiago 6 de noviembre de 2009 (apelación), en: Thomson Reuters Westlaw - CL/JUR/3070/2009.

DHL WorLdWIDE EXPRESS CHILE LTDA. (2009): Corte de Apelaciones de Santiago 10 de noviembre de 2009 (casación y apelación), en: Thomson Reuters Westlaw - CL/JUR/3279/2009.

Consorcio Allianz De Seguros Generales S.A contra Lanchile S.A. (2010): Corte Suprema 13 de enero de 2010 (casación), en: Thomson Reuters Westlaw - CL/JUR/370/2010.

Sudy MÁrquez, EnRIQue Eugenio René con LAN ChILE (2010): Corte de Apelaciones de Coyhaique 20 de abril de 2010 (apelación), en: Thomson Reuters Westlaw - CL/JUR/2639/2010.

IBERIA LínEAS AÉREAS DE ESPAÑA CONTRA Alimentos y FRUTOS S.A. (2010): Corte Suprema 10 de mayo de 2010 (casación), en: Thomson Reuters Westlaw - CL/JUR/2557/2010.

ROHDE AND LIESENFELD TRANSPORTES INTERNACIONALES LIMITADA CON CENTRO DE MEJORAMIENTO GENÉTICO Y RePRoducCión AVANZADA de CAMÉlIDOS LIMITADA (2010): Corte Suprema 22 de julio de 2010 (casación), en: Thomson Reuters Westlaw - CL/JUR/11898/2010.

LAN Airlines S.A. con Soto HeRnÁndez, LeOnel (2010): Corte de Apelaciones de Coyhaique 25 de agosto de 2010 (apelación), en: Thomson Reuters Westlaw - CL/JUR/6280/2010. 
G.I.E.A con Ultramar AgenCiA MARítima LtdA. (2010): Corte Suprema 15 de septiembre de 2010 (casación), en: Vlex - 333045566.

Royal y Sun Alliance Seguros Chile S.A. con Societe Air France (2010): Corte de Apelaciones de Santiago 10 de diciembre de 2010 (apelación), en: Thomson Reuters Westlaw CL/JUR/10658/2010.

PAULINE JeANNERET ELSNER (2011): Tribunal Constitucional 20 de enero de 2011 (requerimiento de inaplicabilidad por inconstitucionalidad), en: Vlex - 311986950.

Seguros Previsión Generales S.A. con Panalpina Chile Transportes Mundiales LtdA. (2011): Corte Suprema 23 de marzo de 2011 (casación), en: Thomson Reuters Westlaw - CL/JUR/2453/2011.

La Interamericana Cía. de Seguros Generales C. LAN Chile S.A. (2011): Corte Suprema 6 de abril de 2011 (casación), en: Thomson Reuters Westlaw - CL/JUR/2982/2011.

La Interamericana Cía. de Seguros Generales con Línea Aérea NaCional S.A (2011): Corte Suprema 20 de abril de 2011 (casación), Rol № 6237-2009, en: Vlex - 333033082.

Chilena Consolidada Seguros Generales S.A con Lan Airlines S.A (2011): Corte Suprema 11 de agosto de 2011 (casación), en: Vlex- 33763878.

LAN AIRLINes S.A. CON SUSACASA MASONE JAVIER ANTONIO y OtRos (2012): Corte de Apelaciones de Santiago 12 de abril de 2012 (apelación), en: Thomson Reuters Westlaw - CL/JUR/919/2012.

Muñoz Sardá María Pilar con Iberia Líneas Aéreas de EsPaña S.A. (2012): Corte de Apelaciones de Valparaíso 19 de junio de 2012 (apelación), en: Thomson Reuters Westlaw - CL/JUR/1628/2012.

RVSG SEefoOd LIMITADA (2013): Corte de Apelaciones de Santiago 21 de octubre de 2013 (apelación), Rol № 2400-2012, en: Vlex -567246398.

Cristian Esteban Rodríguez Salcedo con lan Airlines S.A (2014): Corte de Apelaciones de Concepción 11 de abril de 2014 (Recurso de Apelación, querella infraccional y demanda civil), en: https://westlawchile.cl/, Cita Online: CL/JUR/1255/2014.

Santa Rosa Chile Alimentos S.A con lan Airlines S.A. y DHL Global Forwarding (ChIle) (2014): Corte de Apelaciones de Santiago 27 de junio de 2014 (apelación), en: Vlex-518040854.

Megafrut Limitada con Andes LogISTICS De CHILE S.A. (2014): Corte Suprema 28 de octubre de 2014 (casación), en: Vlex-541162618.

URsula DuRÁn Cepeda con latam AirLines Group S.A. (2016): Corte de Apelaciones de Arica 7 de julio de 2016 (apelación), en: Vlex - 646918161.

ElizABEth Oliveros Con LATAM AirLines Group S.A. (2017): Corte de Apelaciones de Antofagasta 14 de febrero de 2017 (apelación), en: Vlex - 665360697.

LoReto Belén Vera Basualto con Despegar. com y Aerovías del Continente Americano S.A. (2017): Corte de Apelaciones de Antofagasta 12 de mayo de 2017 (apelación), en: Vlex - 679029729.

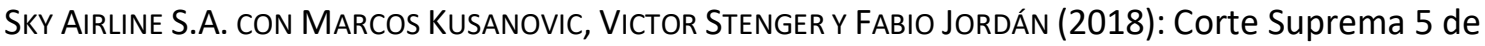
marzo de 2018 (queja), en: Thomson Reuters Westlaw - CL/JUR1029/2018.

Alvaro Guillermo Rojas Muñoz y Ester de las Mercedes Pardo Riquelme con Latam AirLines Group S.A. (2019): Corte Suprema 7 de marzo de 2019 (casación), en: Thomson Reuters Westlaw CL/JUR/1124/2019.

Miguel Alberto Palma Morales con latam Airlines Group S.A. (2019): Corte de Apelaciones de Punta Arenas 21 de agosto de 2019 (apelación), en: https://bit.ly/3fEizH2.

Despegar.com Chile Spa con Ministros Segunda Sala Corte de Apelaciones de Arica (2019): Corte Suprema 22 de agosto de 2019 (queja), en: Thomson Reuters Westlaw - CL/JUR/4792/2019. 
CÓdIGO DE COMERCIO.

Código CIVIL.

DECRETO № 56, del Ministerio de Relaciones Exteriores, que promulga el Convenio de Montreal, para la unificación de ciertas reglas relativas al transporte aéreo internacional, de 24 de marzo de 2009. Diario Oficial, 19 de mayo de 2009.

LEY № 18.046, sobre sociedades anónimas. Diario Oficial, 22 de octubre de 1981.

LEY № 18.916, que aprueba el Código Aeronáutico. Diario Oficial, 08 de febrero de 1990.

LEY № 19.496, sobre protección de los derechos de los consumidores. Diario Oficial, 07 de marzo de 1997.

LEY № 19.857, sobre Empresas Individuales de Responsabilidad Limitada. Diario Oficial, 11 de febrero de 2003.

LEY № 20.831, que modifica el Código Aeronáutico en materia de transporte de pasajeros y sus derechos. Diario Oficial, 30 de abril de 2015. 